\title{
Violencia, mito y sabotaje en Cóbraselo caro, de Élmer Mendoza
}

\author{
Manuel Asensi Pérez \\ Universitat de València \\ asensiperez@gmail.com
}

Resumen: Siguiendo los fundamentos de la crítica como sabotaje, este ensayo analiza la novela de Élmer Mendoza, Cóbraselo caro, como un efecto performativo de la lectura de la novela de Juan Rulfo, Pedro Páramo. A través del estudio de las relaciones lingüísticas, temáticas y situacionales entre esas dos novelas, muestra que Cóbraselo caro, aun siendo un efecto performativo de Pedro Páramo, supone el auto-sabotaje de Élmer Mendoza en relación a buena parte de su narrativa. Pone de relieve, además, que ese auto-sabotaje se lleva a cabo a través del empleo del mito prehispánico de los huesos que se convierten en piedras curativas como una forma de limpieza de la violencia presente en la sociedad mexicana.

AbSTRACT: Taking into account the foundations of Criticism as sabotaje, this essay aims to analyze Élmer Mendoza's novel Cóbraselo caro as a performative effect of Juan Rulfo's novel Pedro Páramo. Through the study of linguistic, thematic and situational relationships between these novels, shows that even if $C o$ braselo caro is a performative effect of Pedro Páramo, implies Elmer Mendoza self sabotaje in relation to many of his narrative work. It points out also that such a self-sabotage is carried out through the use of the Prehispanic myth of the bones becoming healing stones as a path for cleaning the violence in mexican society.

Palabras Clave: Élmer Mendoza, crítica como sabotaje, mito prehispánico, historia de la literatura mexicana, performatividad.

KeYwords: Élmer Mendoza, Criticism as sabotaje, Prehispanic myth, History of Mexican Literature, Performativity.

Entre los efectos performativos reales que provoca un discurso literario se encuentra la acción de escribir una novela que está totalmente modelizada por ese discurso literario anterior. ${ }^{1}$ Que un texto se halle modeli-

\footnotetext{
${ }^{1}$ Esta acción es atribuida por Schmidt y la teoría empírica de la literatura al actante "transformador" (véase Schmidt 1980).
} 
zado por otro no significa que no le añada ningún hilo, que no le meta la mano o que no lo dé a leer (Derrida 1972a: 71 ), ${ }^{2}$ sino que el nuevo texto ha cedido ante el modelo de mundo del texto anterior, lo repite y convierte en tema el hecho de haber sido modelizado. Es lo que ocurre con la novela de Élmer Mendoza Cóbraselo caro (2005), la cual tiene su origen explícito en la obra de Juan Rulfo Pedro Páramo (1955). Tiene su origen y está totalmente enmarcada, absorbida y obsesionada por esa novela, hasta el punto de que sus movimientos lingüísticos circulan muy cerca de ella, como tendremos ocasión de comprobar.

Se podría decir que el texto de Mendoza supone una reflexión acerca de la capacidad modelizadora y narcotizante de Pedro Páramo (en adelante $P P$ ). De hecho, es la historia de un hombre llamado Nicolás Pureco, que sufre de una aparente pérdida de memoria y que se obsesiona con la reconstrucción de los huesos-piedras del personaje Pedro Páramo. Ese es uno de los hilos fundamentales que Cóbraselo caro añade a PP. Esta última novela no toma como objeto de reflexión el poder modelizador de la literatura. En cambio, la primera sí, haciéndose la siguiente pregunta: ¿Qué puede hacerle la literatura a un hombre o a una mujer? En eso la pregunta de Élmer Mendoza es la misma que se hace la crítica como sabotaje: ${ }^{3}$ ¿Qué puede la literatura y el discurso en general? Al plantear esta cuestión, Cóbraselo caro construye un doble espejo: en el nivel de la historia narrada cuenta lo mismo que le ha sucedido a la enunciación: Nicolás (y otros personajes que rondan por los

\footnotetext{
${ }^{2}$ En efecto, Derrida escribe: "Réservant toujours une surprise à l'anatomie ou à la physiologie d'une critique qui croirait en maîtriser le jeu, en surveiller à la fois tous les fils, sans mettre la main à l'"objet", sans se risquer à y ajouter [...] quelque nouveau fil. Ajouter n'est pas ici autre chose que donner à lire" [la cursiva es mía].

${ }^{3}$ Los principios de la crítica como sabotaje quedaron expuestos en mi libro Crítica y sabotaje (2011), así como en el número monográfico de la revista Anthropos. Cuadernos de cultura crítica y conocimiento (2013), con el título de "La crítica como sabotaje de Manuel Asensi", que reveló el trabajo de un grupo de la Universidad de Valencia y de la Universidad Autónoma de Barcelona, que trabajan en torno a las ideas de ese planteamiento. A grandes rasgos, y de forma muy esquemática, se puede decir que la crítica como sabotaje descansa en cuatro puntos esenciales: 1) el carácter apelativo, incitativo y performativo de los discursos, cuya capacidad de modelización de las subjetividades es algo patente; 2) la idea de que todo texto presenta un "modelo de mundo" que afirma o desmiente los modelos de mundo de lo/as lectore/as; 3) la afirmación de la estructura silogística y entimemática de los discursos; y 4) la concepción doblemente conceptual y afectiva de los textos artísticos (lo que se denomina "afepto"), que rompe con toda presuposición esteticista de la obra literaria, fílmica, etcétera.
} 
pueblos fantasmagóricos de México con un ejemplar de Pedro Páramo) está tan obsesionado con Pedro Páramo, como lo está Élmer Mendoza. En consecuencia, Cóbraselo caro (en adelante $C c$ ) representa el gesto auto-reflexivo de un texto literario en torno al poder performativo del discurso literario. Y por eso mismo puede ser considerado un texto "cervantino". 4

Comencemos por los títulos. Estos presentan una gran variedad funcional, mantienen una relación extraña con el llamado "texto principal", máxime cuando, como ocurre en este caso, el título de la novela de Mendoza está extraído de unas palabras que la madre de Pedro Páramo le dice poco antes de morir y le conmina a ir a Comala: "No vayas a pedirle nada. Exígele lo nuestro. Lo que estuvo obligado a darme y nunca me dio... El olvido en que nos tuvo, mi hijo, cóbraselo caro" (Rulfo: 65). La intertextualidad de $C c$ con $P P$ consiste en ubicar como título las palabras del personaje de esa novela, pero esa repetición no se limita a una simple reproducción. Es toda una declaración de intenciones en torno al modelo de mundo que va a presentar la novela de Mendoza, que va a hacerle tomar una dirección distinta a la de $P P$.

Lo primero que designa el título es que $C c$ es, en dos niveles, el resultado de la acción performativa de PP. En un primer nivel, el autor Élmer Mendoza ha sufrido las consecuencias de la lectura y relectura de la novela de Rulfo, hasta el extremo de hacer un alto en el camino de su producción literaria, muy centrada en la temática del narco en México y Estados Unidos. Entre el zurdo Mendieta y David Valenzuela, se cuela Nicolás Pureco. Entre El amante de Janis Joplin (2001), Efecto tequila (2004) y Balas de plata (2008), e incluso Nombre de perro (2012), aparece esta breve novela que viene a alterar (sabotear, diremos después,

${ }^{4}$ En clara referencia a Alonso Quijano, quien sufre un trastorno a causa de la lectura de los libros de caballería que le llevan a cometer lo que las personas de su entorno consideran "locuras". Del mismo modo, Nicolás Pureco, a causa de la lectura de Pedro Páramo se ve llevado a realizar, lo que en opinión de su mujer y otros, son "locuras". En este sentido, todo texto que tematice la determinación de los actos de un sujeto por la lectura puede ser considerado "cervantino". 
auto-sabotear) el modo de significación, el silogismo y el modelo de mundo del resto de su obra.

En un segundo nivel, el personaje de Nicolás Pureco ha sufrido unas consecuencias catastróficas a causa de la lectura de PP. Así lo describe su mujer en el estilo indirecto libre empleado por la narración:

Hacía años que su esposo no era el mismo, desde que se obsesionó con la búsqueda del cuerpo de Pedro Páramo, su contacto con la realidad resultaba muy singular y ella había dejado de preguntarle. Era una maldita locura y cada que podía se lo restregaba en la cara: Tienes tus negocios, tus buenas relaciones, tu futuro asegurado, ¿por qué te ocupas de estupideces?, ¿por qué las buscas?, ¿no te basta con las que la vida te da?, ¿te estás metiendo algo? (Mendoza 2005: 18).

He aquí descrito con detalle uno de los puntos esenciales de la crítica como sabotaje: el silogismo imaginario propio de la literatura y el arte posee la capacidad apelativa, incitativa y performativa de modificar la subjetividad y el comportamiento de quienes entran en contacto con esos dispositivos. Lily asegura que "su esposo no era el mismo", que anda metido en el empresa de hallar el cuerpo de Pedro Páramo, y hasta le pregunta si se está metiendo alguna cosa. Ella ha detectado el poder narcótico de esa novela, ${ }^{5}$ y la forma en que la mente, el cuerpo y los actos de su marido se han visto modelizados y tranformados ("evidentemente su transformación era radical”, piensa el propio Nicolás [89]). La narración confirma, sin ningún género de dudas, cómo comenzó el desequilibrio de Nicolás: "simplemente leyó la novela siete veces" (39), un síntoma excepcional debido a que, tal y como sigue poniendo de relieve el narrador, no tenía ninguna afección por los libros hasta el momento en que se encontró con PP. En eso, la diferencia con Alonso

${ }^{5}$ De narcoanálisis ha hablado Avital Ronell: "Leaving aside the more obvious examples, we also have 'proper' names: Proust (cortisone abuse), Walter Scott, Charles Dickens, Elizabeth Barrett Browning (frequent recourse to laudanum); Novalis, Kleist, Wakenroder ('soft' drugs); Voltaire and Balzac (coffee). Do these not point to the existence of toxic drive? The need to ensure a temporality of addiction? The history of our culture as a problem in narcotism" (23). De todos modos, Ronell emplea la noción de narcoanálisis para hablar de las adicciones, bien de los autores, bien de los personajes de las novelas (Madame Bovary, especialmente) en relación a las drogas. No se refiere, como en este caso, al poder narcótico y performativo del discurso. 
Quijano es importante puesto que este sí tenía la afición por la lectura desde tiempo atrás.

Pero en este segundo nivel, la novela va más allá: hace la genealogía de esa capacidad modelizadora de PP. En realidad todo empezó con sus padres, el día en que encargado de trasladar sus cuerpos a México revisa la casa donde vivieron y se encuentra con un ejemplar de la novela de Rulfo:

Mientras disponían los cuerpos para viajar revisé la casa, encontré un ejemplar de Pedro Páramo ¿YY esto? En su habitación; la misma tía, que ese día regresó a Zacapu para siempre, me platicó que lo hojeaban y [...] con los ojos llorosos terminaban diciendo que lo que ahí se contaba era igualito a lo que le había ocurrido a algún amigo y a no pocos miembros de la familia. Tía, pero ellos no sabían leer, Lo mismo digo (32).

Este fragmento pone en relación el modelo de mundo discursivo de Pedro Páramo y el modelo de mundo naturalizado ${ }^{6}$ de los personajes, que más allá de saber leer (Paul de Man decía que no hay que dar por supuesto la posibilidad de la lectura), ${ }^{7}$ saben leer muy bien porque $P e-$ dro Páramo les confirma su modelo de mundo. Al parecer, y al contrario del planteamiento demaniano, los lectores comprenden muy bien los textos que leen.

Además, la narración cierra las puertas a las sospechas de que el cambio de Nicolás Pureco se debe a otras causas como Alzheimer, demencia senil o cualquier otro problema de salud. Así se lo cuenta Lily a su confidente Marsalis: "La semana pasada lo llevé a fuerzas al doctor Allen, lo sorprendente fue que estaba bien, todas sus reacciones eran correctas y en los análisis salió más sano que yo" (57). David Valenzuela, el protagonista de El amante de Janis Joplin sí tenía brotes esquizofrénicos, oía voces y él mismo la denomina "su parte reencarnable", pero nada de eso le ocurre a Nicolás.

\footnotetext{
${ }^{6}$ Para un análisis de la relación entre los modelos de mundo discursivo y los modelos de mundo naturalizado, véase mi texto "Los modelos de mundo de Gus van Sant: Elephant" (2013).

${ }^{7}$ Paul de Man asegura: "No puede haber escritura sin lectura, pero todas las lecturas están en el error porque suponen su propia legibilidad [...] la escritura también puede ser considerada, con todo derecho, como correlato lingüístico de la incapacidad de leer" (232-233).
} 
Y por lo que se ve hay en esta novela pocos personajes que no sean conscientes del poder modelizador y conmocionante de PP. Cuando Nicolás le pregunta a un amigo, que es conocedor de los problemas que aquel arrastra, si ha leído la novela de Rulfo, responde: "Dios me libre, ¿quieres que se me bote el chango como a ti?" (66). Si uno de los significados de "chango" es el de "persona", ${ }^{8}$ se comprenderá de inmediato que el temor que siente por $P P$ es que le trastorne su personalidad. Así, huye de ella como del diablo. Lo mismo le ocurre a un camarero que está sirviendo a Nicolás y a Macedonio Fernández en un restaurante japonés. El primero le pregunta al segundo si ha leído Pedro Páramo. Y el narrador comenta: "Al escuchar el nombre el mesero que los atendía soltó el plato de sashimi que no se rompió porque era de plástico" (28).

Como es lógico, hay un personaje que hace de contrapunto a esa posición y que por ello mismo la vuelve, por efecto de una différance (Derrida 1972b), mucho más significativa. Lily, la mujer de Nicolás, no comprende ni lo más mínimo la fascinación que ejerce sobre su marido esa novela. La razón es que su modelo de mundo naturalizado, plenamente dentro del sistema de valor, de disposición poco inclinada al feminismo (de los machos dice que solo sirven para el sexo [15]), entra en conflicto con el modelo de mundo y el modo de representación de $P P$. Veamos sus palabras:

es el libro que lo deschavetó. Es muy raro, nunca sabes quién habla, dónde están, a qué hora, y aunque no hay gente mojada llueve casi siempre. Me trauma, no sé qué historia me está contando, lo único que entiendo más o menos es el caso del cura que ha sido atropellado por don Pedro, que a su vez vive perdidamente enamorado de una mujer que no le corresponde... (70-71).

La trauma, no de forma semejante a su marido, sino porque no puede sentirse afectada por la escritura de Juan Rulfo, de quien además sabe poco ("Consulté en internet sobre el autor, dice que nació en Sayula, Jalisco" [71]) y le resulta del todo ajena ("Son tan raros estos mexicanos" [71]).

\footnotetext{
${ }^{8}$ Según el Diccionario del español usual en México (422).
} 


\section{III}

Teniendo en cuenta que la subjetividad de Nicolás Pureco ha sido modificada por su insistente lectura de Pedro Páramo, no resulta nada extrańo que una de las preguntas que vuelven una y otra vez a su mente sea un eco de unas palabras de esta novela. En su fuero íntimo, una intimidad que nos llega a través de un narrador exterior, no cesa de hacerse la siguiente pregunta: "Si la velocidad de la luz es de $300 \mathrm{mil}$ kilómetros por segundo, ¿cuál es la de la oscuridad" $(11,16,37,38$, $53,61,90,115$, etc.), la cual es semejante a la que el narrador en primera persona de $P P$ se hace tras despertar y oír solo el rumor del silencio: "No, no era posible calcular la hondura del silencio..." (Rulfo: 93). Aunque Nicolás Pureco transforma el espacio de la pregunta de Juan Preciado en tiempo, las dos surgen de una consideración sublime (en sentido kantiano) del silencio. Tanto uno como otro se encuentran muy a menudo con el silencio, el de la soledad y el de la noche, el que sirve para borrar la diferencia entre la vida y la muerte, entre los que están vivos o vivas y los que están muertos o muertas, entre el presente y el pasado, entre lo que está cerca y lo que está lejos, entre el fort y el $d a$ del que habla Freud en "Más allá del principio del placer" (90-94) entre el exterior y el interior, convirtiéndose de esa manera en una fuente de indecidibilidad (Derrida 1972b).

El que las dos novelas comiencen con un encuentro con la figura de la madre (Juan Preciado) y con la de sus dos padres (Nicolás Pureco) forma parte de la conexión entre una y otra novela. La madre de Preciado se está muriendo, y los padres de Nicolás están ya muertos cuando se le aparecen, pero en ambas situaciones las figuras familiares hacen un reclamo: a Juan Preciado que busque a Pedro Páramo, a Nicolás Pureco que ya le ha llegado su hora. Sin embargo, este último, consciente de que aquel no llegó a encontrar a Pedro Páramo (cuando llegó a Comala este era ya un lugar de fantasmas), siente la encomienda de encontrar el cuerpo de ese personaje. A partir de ese momento mirará el mundo con los ojos conformados por la novela de Juan Rulfo.

Y llegamos a un punto clave en lo que se refiere a la utilización de un mito prehispánico. Abundan en $P P$ las imágenes de figuras de personas vistas que, de repente, desaparecen, "al cruzar la bocacalle vi una señora envuelta en su rebozo que desapareció como si no existiera” (Rulfo: 70), o de personas que hablan con Juan Preciado y más tarde descubre que 
están muertas y son almas que van penando. En $C c$ leemos situaciones semejantes: "Yo soy Pedro Páramo, dijo Pedro Páramo y desapareció" (Mendoza 2005: 67). Y, en ambas novelas, los muertos hablan desde sus tumbas y cuentan las torturas que sufrieron (116). Hay un momento contundente en el que el protagonista de $P P$ le dice al arriero:

- No, yo preguntaba por el pueblo, que se ve tan solo, como si estuviera abandonado. Parece que no lo habitara nadie.

-No es que lo parezca. Así es. Aquí no vive nadie.

— ¿Y Pedro Páramo?

—Pedro Páramo murió hace muchos años (Rulfo: 69).

También en $C c$ hay una escena semejante. Llega Nicolás a una encrucijada, y pregunta a unos hombres por el pueblo de Baimena:

Buenas noches, señores, ¿a cuántos kilómetros se encuentra Baimena? No sabemos, señor, aquí la distancia se mide por horas o por días de camino, O por subidas y bajadas, He oído que está lejos, dijo otro, Como quince días o más, y se fueron alejando rumbo a La Media Luna, Ese hombre debe estar loco, alcanzó a escuchar (Mendoza 2005: 96-97).

Al margen de que esos individuos se dirigen hacia la hacienda donde vivía Pedro Páramo, resulta evidente que su existencia, igual que la de La Media Luna es dudosa. A ello se suma el hecho de que muchos de los personajes con los que se encuentra Pureco están o muertos o son fantasmas: "Vaya que se encontraron, ¿han pensado en Baimena?, Siempre, sólo que es para los pétreos, nosotros somos polvo. Y flotaron, creando una leve turbiedad similar al talco" (Mendoza 2005: 116-117).

\section{IV}

Referirme a este nivel de relaciones lingüísticas, temáticas y situacionales, entre una novela y otra, y son muchas las citas, alusiones, referencias de Mendoza a Rulfo, ${ }^{9}$ muy en especial en lo que se refiere al topos de ambas novelas, se debe justo a que es necesario señalar una diferencia

\footnotetext{
${ }^{9}$ Sobre la intertextualidad en la narrativa de Élmer Mendoza, y en especial en $E l$ amante de Janis Joplin véase Castañeda Hernández (2009-2010).
} 
importante. $C c$ comienza allí donde acaba $P P$, no solo porque tanto la primera novela como la historia ahí narrada son una acción cuya causa es el sistema modelizante representado en la segunda, sino porque la última frase de $P P$ da lugar al inicio de $C c$. Vamos a analizarlo con detenimiento. La muerte de Pedro Páramo, en el eje temporal del pasado, se describe del siguiente modo: "Después de unos cuantos pasos cayó, suplicando por dentro; pero sin decir una sola palabra. Dio un golpe seco contra la tierra y se fue desmoronando como si fuera un montón de piedras" (Rulfo: 178).

Rulfo emplea un símil para describir la caída de Pedro Páramo, para crear el efecto de desmoronamiento del personaje. El lector o la lectora "oyen" la caída de ese cuerpo. Acompañado por una muerta, Damiana Cisneros, que en la posición de Caronte le invita al mundo de los muertos, Pedro Páramo se desmorona. La mención de las "piedras", última palabra de la novela de Juan Rulfo, forma parte de una estructura comparativa claramente marcada por ese "como si". Nada se dice en el texto acerca del lugar donde enterraron a Pedro Páramo, ni siquiera si llegaron a enterrarle. Solo una mujer que aparece en Cóbraselo caro explica que aunque hizo mucho daño y nadie lo quería, "nos dio muina verlo en ese estado y le dimos cristiana sepultura" (71-72).

¿Qué hacen ante esto Élmer Mendoza y Nicolás Pureco? Convertir en literal la comparación del narrador de Pedro Páramo que, insistamos, ha tratado de moverse en un plano metafórico. Allí donde la novela de Rulfo dice "como si fuera un montón de piedras", la de Mendoza lo interpreta literalmente: Pedro Páramo se ha convertido en piedras, sus huesos se han convertido en piedras.

El efecto de la lectura de Pedro Páramo, su determinación performativa, su modelización y obsesión, llevan a una interpretación aberran$\mathrm{te}^{10}$ de las palabras del narrador de esa novela. Podría decirse, en un estilo demaniano, que "es posible hacer que dependan de una sola línea de texto dos lecturas enteramente coherentes y enteramente incompatibles entre sî" (Paul de Man: 25), a condición de entender que esa incompatibilidad no termina en sí misma como un callejón sin salida, sino que se origina en la modelización operada por esa novela.

${ }^{10}$ Desde Harold Bloom, Umberto Eco y Derrida esta noción de "aberrante", en tanto desviación, es muy conocida por los especialistas en teoría de la literatura. La cita de De Man es definitiva a este respecto. 
Nicolás Pureco interpreta literalmente el tropo del narrador de $P P$ porque en su guerra con esta novela, su abdicación final y consiguiente fascinación le llevan a intentar buscar el cuerpo de Pedro Páramo. Nos lo confirma el narrador a través de Lily: "Hacía años que su esposo no era el mismo, desde que se obsesionó con la búsqueda del cuerpo de Pedro Páramo" (Mendoza 2005: 18). La crítica como sabotaje no niega el fenómeno de la indecidibilidad tal y como es sostenido por Paul de Man y Jacques Derrida, pero lo reubica poniéndolo por debajo del fenómeno de los modelos de mundo y de los efectos de modelización.

¿Qué significa que Nicolás Pureco se lance a la búsqueda de un cuerpo que, según uno de los personajes de $C c$, fue enterrado hace 80 años? Significa que busca sus huesos, o lo que es lo mismo, las piedras en las que se ha convertido: "En el camino le explicó lo de sus padres, que debía darse prisa con las piedras que le faltaban” (19). Este va a ser el hilo conductor de todos los movimientos de Nicolás. De hecho, hay un momento en que este personaje confiesa a su mujer sus intenciones y cita, además, las palabras finales de PP:

De pronto anunció: Encontraré las piedras del cuerpo de Pedro Páramo sea como sea, ¿Cuándo las perdiste? Lily, que se hallaba malhumorada y recordaba mal su lectura de la novela más importante escrita en español en el siglo xx, pero no así el final, objetó: ¿Qué no se hace polvo?, Pureco sacó de su guayabera un ejemplar bastante maltratado pero no lo abrió, sólo por seguridad pronunció las últimas palabras: "Dio un golpe seco contra la tierra y se fue desmoronando como si fuera un montón de piedras" (Mendoza, 2005: 17).

Esta cita del final de $P P$ no se lee en voz alta solo con la finalidad de centrar el objeto de su búsqueda, sino para contrastarlo con el punto de vista científico de Lily. ¿Acaso los muertos no se convierten finalmente en polvo? Según la ciencia, los huesos tardan entre 40 y 50 ańos en deshidratarse, hacerse quebradizos y disolverse. Por supuesto depende del medio, del Ph o de la acidez (Gordon y Shapiro 1982). De ahí que Lily trate de exponer, aunque sea de forma popular, el punto de vista científico con la finalidad de disuadir a su marido de su interés por encontrar el cuerpo y las piedras de Pedro Páramo. Sin embargo, Nicolás opone al punto de vista científico (al modelo de mundo gobernado por el significado trascendental de la ciencia), el punto de vista 
mitológico (el modelo de mundo guiado por una religiosidad y unas creencias pre-hispánicas).

En el modelo de mundo de PP los muertos hablan con los vivos, y el pasado se entrevera con el presente, y los símbolos (de la tierra, del viento, de las piedras, etc.) abundan tal y como puso de relieve el trabajo de Nicolás Emilio Álvarez (1983). Puesto que Nicolás Pureco, que tenía en Chicago "tres restaurantes acreditados de comida mexicana [...] siete millones de dólares [que le había ganado en una demanda] a una empresa refresquera" y dinero invertido en bienes raíces (Mendoza 2005: 31), se ha visto modelizado por su insistente lectura de Pedro Páramo, el motor de sus actos ha pasado del sistema de valor al sistema mitológico. Y de ese sistema mitológico prehispánico se ha visto afectado especialmente por una de sus dimensiones: la equivalencia entre los huesos de los muertos y las piedras.

En diversos lugares de México, como en Guerrero, el Valle del Mezquital, la región de Actopan, etc., según confirman las publicaciones del Instituto Nacional de Antropología e Historia de la ciudad de México, la creencia de que los huesos de los antepasados se convierten en piedras con propiedades especiales está bien documentada. Galinier (1987), Catherine Good (2001a y 2001b), Johanna Broda (2004 y 2008), Sánchez Vázquez (2004), lo han constatado de diferentes maneras, incluidos los testimonios orales. ${ }^{11}$ Por ejemplo, Good afirma que los huesos y las piedras están relacionados:

Los huesos representan a los ancestros y dan testimonio de su cumplimiento histórico con la obligación humana de alimentar la tierra. También simbolizan el aspecto cíclico de la renovación de la vida humana y del crecimiento de la vegetación [...] Esta identificación entre piedras y huesos humanos podría explicar también la constante asociación de las piedras antiguas con las cruces en los lugares donde el ritual va dirigido a iniciar anualmente el ciclo de cultivo y del trabajo humano colectivo (2001b: 45).

Galinier, por su parte, analiza etimológicamente la palabra del paisaje ritual en Mesoamérica y escribe: "Etimológicamente, el hueso (to’yo) significa 'piedra de esqueleto'. El primer término está asociado a la divinidad suprema, el dueño del universo, y el segundo al mundo de los

${ }^{11}$ Véase la nota a pie de página de Sánchez Vázquez (292). 
muertos" (1987: 496). De todas estas investigaciones antropológicas en torno a la mitología, ritos y creencias de los pueblos prehispánicos de las diferentes zonas de México, se desprende que los huesos devenidos piedras poseen varias funciones: curan, libran de las malas influencias o de los malos aires, sirven de intermediarios entre los dioses y los hombres y, además, depuran los pecados cometidos por la persona a la que pertenecía ese esqueleto. La limpieza del hueso representa la purgación de las posibles malas acciones realizadas por la persona cuando estaba vivo y tenía carne (Broda y Good 2004: 130).

Este mito prehispánico alimenta la lectura literal que Nicolás Pureco hace de las palabras finales de Pedro Páramo, como si el modelo de mundo presentado por Rulfo hubiera provocado el acto auto-reflexivo en virtud del cual un lector o lectora puede llegar a prescindir de una concepción oblicua del lenguaje. Curiosamente, la doctora Isabel Campuzano, reputada bioquímica de la Universidad de Michigan, aparece como un personaje que desde la institución universitaria corrobora y comparte el interés por los huesos-piedra de Pedro Páramo.

Esta profesora, movida por intereses "científicos", apoya y anima a Nicolás para que prosiga su búsqueda: "Era emprendedora y miraba de frente. Le propuso que le llevara el material allí, utilizarían los laboratorios de la universidad y a su equipo: tendrían resultados expeditos" (Mendoza 2005: 35). En uno de los tantos reproches de su mujer que trata por todos los medios de que desista en su búsqueda, responde: "tengo el apoyo de la doctora Campuzano para el análisis de las piezas" (63). Nicolás se aprovecha del vínculo que el personaje de la científica establece entre la tecnología y la mitología, porque aunque la doctora persigue una importante fama derivada de sus investigaciones, él va guiado por otro motivo que ahora trataremos de analizar.

Nicolás va consiguiendo las piedras poco a poco y con dificultad, después de múltiples entrevistas, caminatas por paisajes desolados, y viajes por los lugares de las tierras de Juan Rulfo. "Eligió la habitación de los huéspedes para formar el cuerpo de Pedro Páramo. Las piedras fueron llegando una a una, chicas y grandes, pardas y rojizas, secas y resecas. Con una brocha muy fina las limpiaba y les buscaba acomodo con las 
otras" (43). ¿Por qué piensa que "la idea de encontrar las piedras del cuerpo de Pedro Páramo [era] lo mejor que había pensado en su vida"? (49). ¿De dónde surge el impulso que le mueve bajando y subiendo cerros?

Su objeto, por decirlo en términos narratológicos, lo persigue a pesar incluso de que recibe amenazas: "Sabemos en lo que anda Pureco, y le pedimos, no, espere, le ordenamos que suspenda su búsqueda, deje a los muertos en paz [....] si se empeña, agárrese, porque acabaremos con usted más pronto de lo que imagina" (23). Esta amenaza es muy significativa aunque ocupe un fragmento bastante corto en el conjunto de la novela, pues se trata de la inscripción en este texto de un motivo repetido en la obra de Mendoza: la violencia propia de la guerra del narco y todo el reguero de muertos que va dejando detrás. En cualquiera de las novelas anteriores y posteriores el lector encontrará esa violencia y esa sangre, producto de las mafias asociadas al narco, incluidas la policía, los políticos y los jueces.

Así, por ejemplo, en Nombre de perro, tras una escena de venganza en la que unos personajes llamados el Diablo y el Chóper torturan al Gori lanzándole "un balde de agua fría" y conectándole "un electrodo de una pierna", nos encontramos a Ugarte, su mujer María y su hija Francelia conduciendo hacia Mazatlán. Los detienen unos miembros de la policía federal, que una vez les interrogan sobre su destino, les espetan el siguiente discurso:

Qué Mazatlán ni qué la chingada, ustedes hasta aquí llegan, bájense y no toquen nada, dejen bolsos, celulares, dinero, lo que traigan. Pero. Por favor, mi esposo está muy enfermo, suplicó María. Pues va a ser el primero en bajar, y apúrese que no tenemos su pinche tiempo o aquí se les acaba el corrido. No sea inhumano, vea cómo está. Cierra la boca piche vieja, si no me lo chingo para ahorrarle sufrimiento, le mostró un AK-47 [acrónimo de un fusil de asalto soviético inventado por Kaláshnikov]. Y a ti y a la morra les pegamos una cogida de aquellas pa que no anden diciendo que no las tomamos en cuenta (Mendoza 2012: 167).

No hace falta recordar que esta escena de amenazas, falta de respeto y robos, está lo suficientemente cerca de la realidad fenoménica como para ser reconocido por cualquier ciudadano/a mexicano/a. Estar cerca no significa que las novelas de Mendoza reflejen la realidad, ello 
sería imposible para cualquier entidad semiótica. La teoría pictórica de la verdad del lenguaje, tal y como quedó expuesta por Wittgenstein (1922) en el Tractatus, ${ }^{12}$ ignora el hecho fundamental de que todo signo es en su misma constitución una metáfora de la cosa que describe. Lo que se pretende apuntar con ese "estar cerca" es que la narrativa de Mendoza apunta hacia ese agujero de lo real (Lacan) que representa la violencia. En una entrevista publicada en 2008, el mismo Élmer Mendoza habla de esa violencia en los siguientes términos: "Mi teoría sobre esto es que hay una violencia tradicional [...] Es una violencia que escapa a las drogas que es... Prolija sicarios diferentes los colombianos que matan con balas rezadas, que van y se encomiendan a Dios pero luego son cruelísimos a la hora de matar. Es como una ultraviolencia” (Rey Pereira: 338). En esa misma entrevista habla de México como de un "estado de excepción emocional".

El entrevistador de Mendoza le hace notar que Cóbraselo caro es una novela diferente a las anteriores (339), y está en lo cierto, aunque no por las razones que dan ni él ni el propio Mendoza. Este asegura que para la construcción del personaje de Nicolás Pureco se basó en algunas personas reales que, siendo mexicanos de origen y habiendo vivido en Estados Unidos vendieron todas las empresas que poseían en este país y volvieron a su lugar de origen. En este argumento se basa Mendoza para afirmar que la intención de Cóbraselo caro era "hacer una parábola del regreso total” (341). Nadie puede negar que esta novela cuenta la historia de un regreso, pero su silogismo va en otra dirección por mucho que Mendoza pueda no ser consciente de ello. Aclarémoslo: $C c$ plantea un silogismo consistente en bucear en las raíces de la violencia mexicana, representada por Pedro Páramo, y tratar de lavarla a través de unos huesos ya limpios que se han desecho de la maldad y del rencor.

El uso del mito prehispánico de los huesos que se convierten en piedras, y la reconstrucción que lleva a cabo Pureco funcionan como la alegoría de un deseo espeluznante de desprenderse de una violencia atávica que se manifiesta en toda su crueldad en la realidad mexicana actual. La violencia posmoderna (Zizek 2004) va hasta el fondo de di-

\footnotetext{
${ }^{12}$ Así, por ejemplo, en 2.022 Wittgenstein escribe: "It is clear that however different from the real one an imagined world may be, it must have something —a form— in common with the real world".
} 
cha violencia atávica en un acto de desesperación narrativa con el fin de ejercer un lavado de una mancha patente.

En la novela que estamos analizando hay varios pasajes que prueban lo que acabo de argumentar a propósito de su silogismo fundamental. Un personaje apodado "el indio" le dice a Nicolás lo siguiente acerca de Pedro Páramo: "es la más viva tentación humana de poder absoluto" (Mendoza 2005: 37). ${ }^{13} \mathrm{Y}$ una mujer que le refiere que los restos de Pedro Páramo se encuentran en Baimena, dice: "Hizo mucho daño y nadie lo quería [...] No le pusimos cruz porque queríamos borrar su nombre" (71-72). Estas frases, breves, como dichas de paso por personajes secundarios, son fundamentales para entender el silogismo de esta novela. Indican que Pedro Páramo representó el intento fascista y caciquil de tener el poder absoluto y de ponerse en el lugar de un dios demoníaco hacedor del mal; dan a entender todo el daño que causó, tanto que nadie le quería y lo que más deseaban era borrar su nombre de la faz de la tierra.

La forma en que Mendoza proyecta sobre el presente el mito prehispánico de los huesos que al convertirse en piedras adquieren un poder curativo, reescribiéndolo, dando lugar a la reconstrucción del esqueleto-piedra de Pedro Páramo, tiene el sentido del deseo desesperado de una limpieza y una curación de una sociedad en estado terminal. Ese es el silogismo que genera y estructura toda la trama narrativa de Cóbraselo caro. En tanto alegoría tiene el problema de prestarse a interpretaciones de toda índole, incluida la que doy aquí, sobre todo porque como tal supone una reflexión acerca del resto de las novelas del mismo autor.

En el ciclo de novelas que de una forma u otra giran alrededor de la violencia y del narcotráfico, Cóbraselo caro atraviesa todos esos textos para preguntarse, por un lado, por la génesis de la violencia mexicana y, por otro, para manifestar el deseo de una limpieza hallada en el modelo de mundo de una mitología prehispánica que aún no había desgranado esa ultraviolencia de la que habla Mendoza.

${ }^{13}$ Sobre el poder en la narrativa de Mendoza véase Guzmán 2004. 
Al decir que Cóbraselo caro atraviesa su narrativa anterior tomándola como objeto de reflexión, se da a entender que se convierte en una metanarración en varios sentidos (básicamente respecto a Pedro Páramo y respecto a su producción novelesca dominante), y que lleva a cabo un auto-sabotaje, un sabotaje reflexivo que pone en tela de juicio el modo de representación de su modelo narrativo más conocido. De algún modo bastante efectivo, Cóbraselo caro tiene un efecto desestructurante en buena parte de las novelas que la acompañan, anquilosándolas y haciendo que sus maquinarias se atranquen. Por supuesto no hablo de que tras leer esta obra de Élmer Mendoza el resto de sus novelas pierdan su valor, su capacidad de advertencia en relación a una realidad furiosa, o que no vayan a dejar de circular en el mercado editorial. Al contrario, serán leídas con la misma o más intensidad, pero ello es síntoma de que su modo de representación en tales novelas (Corona 2007) pertenece a un registro hegemónico, automatizado, y que se puede encontrar en el cine o en las novelas populares de Arturo Pérez-Reverte (quien ha reconocido la deuda de La reina del sur con la obra de Mendoza).

Sin querer demorarme en exceso en este punto, que merecería una atención cuidadosa y lenta, en un estilo derridiano trataré de explicarlo dando las claves fundamentales de este argumento. Tomemos como ejemplo una novela como El amante de Janis Joplin (2001). El narrador de este texto mezcla la descripción de las situaciones objetivas ("El tiempo no iba a detener a las parejas que bailaban bajo la magia de la Luna en lo alto de la sierra, a la entrada de un cobertizo semioscuro donde sólo había una grabadora y un caset" [11]), la subjetividad de los personajes a través de la que se perciben sus procesos interiores (“¿Quién necesita más?, pensaba Carlota Amalia Bazaine mientras observaba a los mozos que hacían macherías fuera del baile" [11]; "le respondió la voz: David, ¿̇me oyes? La voz, que podría ser la de una mujer que habla grueso o la de un hombre delicado, habitó completamente su cabeza" [18]), y los diálogos de los personajes insertados en las líneas de la prosa horizontal ("Abran paso, dijo alguien y David reconoció la voz de su padre, Papá, no quiero condenarme, ¿Condenarte? Olvídate, si te agarran te van a matar" [19]).

Al mismo tiempo, estos tres niveles narrativos se estructuran a través de unas series progresivas en las que cada apartado va avanzando en las aventuras que vive el personaje de David Valenzuela desde que se escapa de México y llega a California, se convierte en jugador de béisbol, 
se enamora de Janis Joplin, etc. La dinámica de lo que la lingüística denomina "tema/rema" se convierte en el eje de esa progresión en la que el sintagma y la metonimia predominan. ¿Qué conclusión se puede extraer de estos datos de orden narratológico? La de que Élmer Mendoza emplea un modelo narrativo hegemónico que no es muy diferente de una serie televisiva de moda, un film de Tarantino o Ridley Scott, o las novelas de Don Winslow.

Si ahora nos fijamos en el modo de representación de Cóbraselo caro nos daremos cuenta de los cambios que introduce en el anterior esquema narrativo. Aunque el narrador sigue combinando la descripción en tercera persona, el retrato de la subjetividad y los diálogos inscritos en la línea horizontal de la narración, sus series ya no son progresivas, sino repetitivas. Es cierto que Nicolás Pureco va en pos de la recuperación del cuerpo de Pedro Páramo, y que para ello realiza un viaje, pero la acción de la novela parece no avanzar. La desorientación de Pureco, su pérdida de la memoria, su confusión en torno a los vivos y los muertos, al pasado y al presente se traduce en una estructura en la que la relación entre Nicolás y las piedras es una situación fija. No es solo que la frase "si la velocidad de la luz es de 300 mil kilómetros por segundo, ¿cuál es el de la oscuridad?” (Mendoza 2005: 16), se repita con diferentes variantes como un estribillo o ritornello de toda la narración.

Además, las situaciones en las que Nicolás se encuentra con las piedras, sus dudas en torno a si son piedras-huesos o simples piedras, sus caminatas por cerros, encrucijadas y pueblos más o menos fantasmales, las respuestas diferentes a sus preguntas por Pedro Páramo (“¡se acuerda que yo quería saber donde había caído Pedro Páramo?, Pedro Páramo, ¿no es un señor de Tolimán? Pureco guardó silencio" [55-56]), le llevan a un conocimiento fallido y negativo en lo que se refiere a esa figura histórica-literaria que él persigue. Mientras el conocimiento y la certeza, si quiera respecto a la violencia, son positivos en la mayoría de las novelas de Mendoza, ${ }^{14}$ en esta el conocimiento y la certeza dan como resultado un conocimiento negativo. Fijémonos en este momento de la novela en que Pedro Páramo aparece y desaparece en un abrir y cerrar de ojos:

\footnotetext{
${ }^{14}$ La distinción entre violencia positiva y negativa se refiere aquí a los datos inmediatos de la conciencia del narrador.
} 
Recogió una roca de buen tamaño, la olió y la guardó en un morral, después giró sobre sí mismo para escuchar mejor los lamentos, encontraría a la señora de las sombras y la llevaría con él, ¿Cómo se llamaba?, para que le dijera quiénes iban y venían por su casa. Tiró la piedra que había recogido y tomó otra, deambuló: recogía y tiraba, recogía y tiraba... (67-68).

Este fragmento marca la pulsión dominante de este texto, la incertidumbre respecto a su objeto de búsqueda, y por ello una repetición opuesta a la progresión de sus novelas habituales. Incluso la doctora Campuzano dirá que las piedras que le va trayendo "tienen todo el aspecto de ser fósiles humanos" (72), pero en ningún momento reconoce que sean de Pedro Páramo. Incluso se incurre en el sinsentido al determinar el origen de las piedras: "Las encontró en macetas, lienzos, calles empedradas y en el jardín de Tiburcio Ávalos; en Acapulco y Tuxcacuesco, en Tonaya y San Gabriel" (77), un sinsentido que recuerda las clasificaciones que Borges describe en "El idioma analítico de John Wilkins". La novela acaba con la repetición de esa Y griega en la que tantas veces se ha encontrado y lo hemos encontrado.

Dicho de otro modo: en ningún momento Nicolás Pureco consigue la certeza de haber reunido el esqueleto-piedra de Pedro Páramo, nada se dice en la novela con rotundidad sobre ello, y acaba con unas palabras que marcan y remarcan la circularidad del tiempo mítico: "Y el camino bajaba, subía y daba vuelta” (123). Por esa razón, el auto-sabotaje de Mendoza tiene el sentido de un deseo desesperado de limpieza en un medio sucio, demasiado sucio.

\section{BibliografíA}

Álvarez, Nicolás Emilio. Análisis arquetípico, mítico y simbólico de Pedro Páramo. Miami: Ediciones Universal, 1983.

Asensi Pérez, Manuel. Critica y sabotaje. Barcelona: Anthropos / Siglo XXI, 2011.

Asensi Pérez, Manuel. "Los modelos de mundo de Gus van Sant: Elephant", en Archivos de la filmoteca. Cine e hibridaciones culturales: avatares de la era digital, núm. 72 (2013).

Broda, Johanna y Good, Catherine (coords.). Historia y vida ceremonial en las comunidades mesoamericanas: los ritos agrícolas. México: Instituto Nacional de Antropología e Historia, 2004. 
Broda, Johanna. "Leonard Schultze-Jena y sus investigaciones sobre ritualidad en la montaña de Guerrero", en Anales de Antropología (2008): 117-145.

Castañeda Hernández, María del Carmen. "El posmodernismo en una visión intertextual de El amante de Janis Joplin de Élmer Mendoza”, en Revista de Estudios Literarios, núm. 43 (2009-2010).

Corona, Ignacio. "Una aproximación a la narrativa de Élmer Mendoza”, en Revista de Literatura Mexicana Contemporánea, núm. 34 (2007): 53-74.

De Man, Paul. Alegorias de la lectura. Lenguaje figurado en Rousseau, Nietzsche, Rilke y Proust. Barcelona: Lumen, 1990.

Derrida, JacQues. La dissémination. Paris: Seuil, coll. Tel Quel, 1972a. Trad. esp. La diseminación. Madrid: Fundamentos, 1975.

Derrida, Jacques. Marges de la philosophie. Paris: Minuit, 1972b. Trad. esp. Márgenes de la filosofía. Madrid: Cátedra, col. Teorema, 1988.

DicCiONARIO DEL ESPAÑOL USUAL DE MÉXICO. Luis Fernando Lara (dir.). México: El Colegio de México, 2009.

Freud, Sigmund. "Más allá del principio del placer", en Psicología de las masas. Madrid: Alianza Editorial (11ª reimpresión), 1987. 81-137.

Galinier, Jacques. Pueblos de la Sierra madre. Etnografía de la comunidad Otomí. México: Instituto Nacional Indigenista / Centro de Estudios Mexicanos y Centroamericanos, 1987 [El original francés es de 1974].

Galinier, JaCQues. La mitad del mundo. Cuerpo y cosmos en los rituales Otomíes. México: Universidad Nacional Autónoma de México / Instituto Nacional Indigenista, 1990.

Good, Catherine. "Osotempan, ombligo del mundo", en Johanna Broda, Stanislaw Iwanisziewski y Arturo Montero. La montaña en el paisaje ritual. México: 2001a. 375-393.

Good, Catherine. "El ritual y la reproducción de la cultura: ceremonias agrícolas, los muertos y la expresión estética entre los nahuas de Guerrero”, en Johanna Broda y Jorge Félix Báez (eds.). Cosmovisión, ritual e identidad de los Pueblos Indígenas de México. México: Fondo de Cultura Económica, 2001b. 239-297.

Gordon, Isidor y Shapiro, Hillel Abbe. Forensic medicine: a guide to principles. Edinburgh, New York: Churchill, 1982.

Guzmán, Nora. "El poder como génesis del asesinato político: 'un asesino solitario’ de Élmer Mendoza”, en Revista de Literatura Mexicana Contemporánea, núm. 24 (2004): 1011-1017.

Mendoza, Élmer. El amante de Janis Joplin, Barcelona: Tusquets, 2001.

Mendoza, Élmer. Cóbraselo caro. Barcelona: Tusquets, 2005.

Mendoza, Élmer. Nombre de perro. Barcelona: Tusquets, 2012. 
Piña, Lorena. "La arquitectura estética en 'el amante de Janis Joplin' de Élmer Mendoza", en Revista de Literatura Mexicana Contemporánea, núm. 24 (2006): 1032-1036.

Ramírez-Pimienta, Juan Carlos. El norte y su frontera en la narrativa mexicana. México: Plaza y Valdés, 2005.

Rey Pereira, Rodrigo. "La condición social de México en los escritos del autor: Entrevista con Élmer Mendoza”, en Anales de la Literatura Hispanoamericana, vol. 37 (2008): 331-342.

Ronell, Avital. Crack Wars. Literature, Addiction, Mania. Lincoln\&London: University of Nebraska Press, 1992.

Rulfo, Juan. Pedro Páramo. Madrid: Cátedra, 2010 (22 ed.).

SÁnchez VÁzquez, Sergio. "Wemas y cagandhos: limpias con piedras en el Valle de Mezquital, Hidalgo", en Johanna Broda y Catherine Good. Historia y vida ceremonial..., 2004. 289-303.

Schmidt, Siegrried. Einführung in die empirische Literaturwissensschaft, Braunschweig. F. Vieweg, 1980. Trad. esp. Fundamentos de la ciencia empirica de la literatura. Madrid: Taurus, 1991.

Wittgenstein, Ludwig. Tractatus Logico-Philosophicus. London: Harcourt Brace \& Company Inc., 1922.

Zizer, Slavoj. Violencia en acto. Conferencias en Buenos Aires. Buenos Aires: Paidós, 2004.

FeCha DE RECEPCIÓN: 17 de junio de 2013

FECHA DE ACEPTACIÓN: 07 de noviembre de 2013 